\title{
Adenocarcinoma of the Colon in a 10-year-old child
}

Siboe M. M., MBChB, Abdalla R. 0., MBBS, MCS (ECSA), Lakati K.C., MBChB, MCS (ECSA), Oduor P., MBChB, MMed (Surg), FCS (ECSA) Correspondence: Dr. M.M. Siboe, P.0. Box 73946-00200, Nairobi, Kenya, E-mail: marxiboy@gmail.com

\section{Summary}

Colonic adenocarcinoma is rare in children, more so in the first decade of life. Owing to the non-specificity and vagueness of symptoms, most patients in this age group present with advanced malignacy. The authors report a case of adenocarcinoma of the colon in a 10-year-old female child presenting with a history of abdominal pain, distention and constipation. Barium enema highlighted a narrowing of the distal ascending colon with laparotomy revealing a growth involving the caecum and ascending colon. Histology confirmed it as a poorly diffentiated mucin secreting adenocarcinoma. A right hemicolectomy with end to end ileotransverse anastomosis was perfomed. Four months later, she presented with symptoms of intestinal obstruction. Intraoperatively, widespread metastatic nodules with recurrent tumour were noted. It is important for clinicians to be aware that colorectal carcinoma does occur in children, and age alone should not be a basis for its exclusion. This case is presented to draw attention to a disease in which the prognosis, by wider recognition of its occurrence in childhood, might be improved.

\section{Introduction}

Colorectal carcinoma is a common visceral malignancy in the adult age group. Few cases have been reported in children and adolescents. Clinical features in childhood are non-specific and therefore tend to be ignored or misinterpreted (1). Only about 400 cases involving subjects less than 20 years were reported in the literature by 1988 , with less than 12 patients below the age of 10 years and the youngest nine months old at the time of diagnosis (2-11). Genetic instability without hereditary nonpolyposis colorectal cancer (HNPCC) is a major mechanism of causation $(12,13)$. In contrast to adult patients, childhood adenocarcinoma is associated with a poorer prognosis and a high index of suspicion is required for early diagnosis.

\section{Case Report}

A ten year old girl presented to our facility with a four months history of abdominal pain associated with distension, constipation, anorexia, weight loss and postprandial emesis. She had received various treatments with only partial relief, for the symptoms and results of stool investigations repeatedly showing pus cells.

Her general condition was good. She was not pale and had no jaundice, lymphadenopathy or dehydration. Her vital signs were as follows: pulse 78/minute, respiratory rate $18 /$ minute, blood pressure $110 / 80 \mathrm{mmHg}$ and temperature $36.5^{\circ} \mathrm{C}$.
Examination of the abdomen revealed a poorly circumscribed and immobile mass in the right iliac fossa. The bowel sounds were present and normal. The liver, spleen and rectum were normal as was the rest of the systemic examination.

She was investigated for a colonic tumour.

The haemoglobin was $10.1 \mathrm{~g} / \mathrm{dl}$; white blood cell count $10 \times 10^{3} / \mu \mathrm{l}$; hematocrit $32.8 \%$; platelets $469 \times 10^{3} / \mu \mathrm{l}$; urea $3.2 \mathrm{mmol} / \mathrm{l}$; creatinine $94.5 \mu \mathrm{mol} / \mathrm{l}$; sodium 140.9 $\mathrm{mmol} / \mathrm{l}$ and potassium $4.3 \mathrm{mmol} / \mathrm{l}$.

Her previous plain abdominal radiographs were normal while ultrasound revealed a right abdominal opacification displacing bowel loops.

A barium enema done indicated easy and free flow of contrast up to the upper ascending colon (fig. 1) with circumferential narrowing of the distal ascending colon (fig. 2). The rest of the colon was normal.

At exploratory laparotomy, there was an iliac fossa mass with enlarged mesenteric nodes. The mass was hard, nodular and involved the caecum and proximal part of the ascending colon (figure 3). The appendix was enlarged and erythematous (figure 4). There was no ascitis. The rest of the viscera were normal.

A right hemicolectomy and end-to-end ileo-transverse anastomosis was performed.

The patient developed cough and fever on the third post operative day with decreased breath sounds over the left posterior lung field and presence of coarse crepitations 


\section{Adenocarcinoma of the Colon in a 10-year-old child}

Siboe M. M., Abdalla R. O., Lakati K.C., Oduor P.

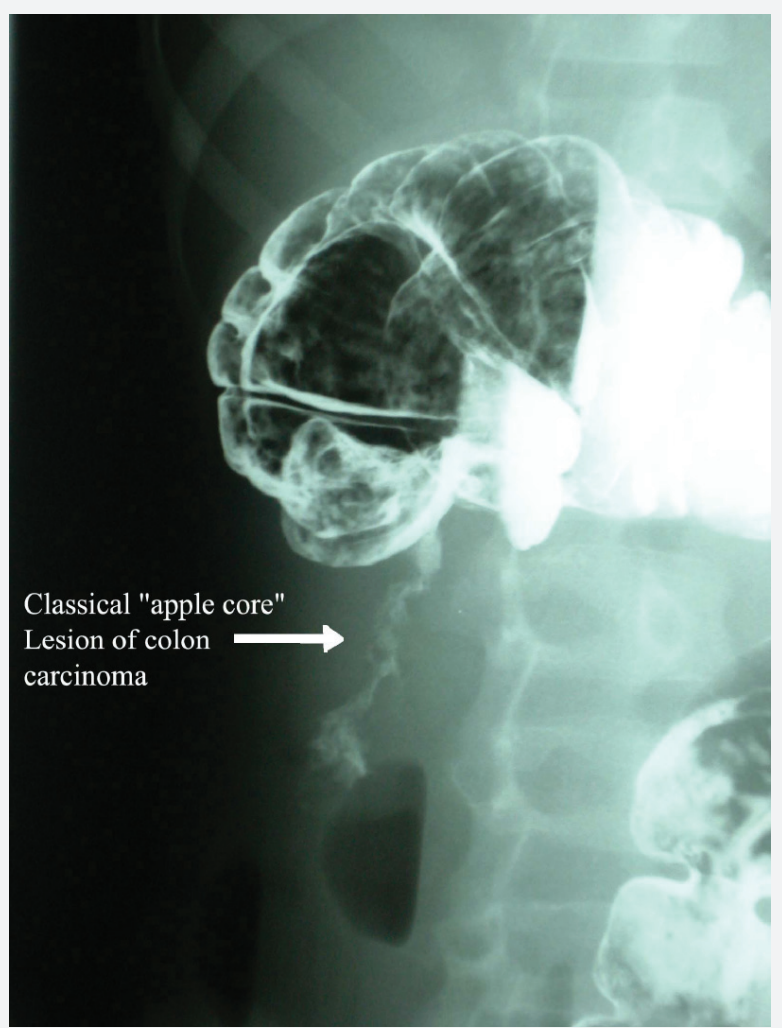
Figure 2: "Apple core" lesion of colon carcinoma with narrowing of distal ascending colon

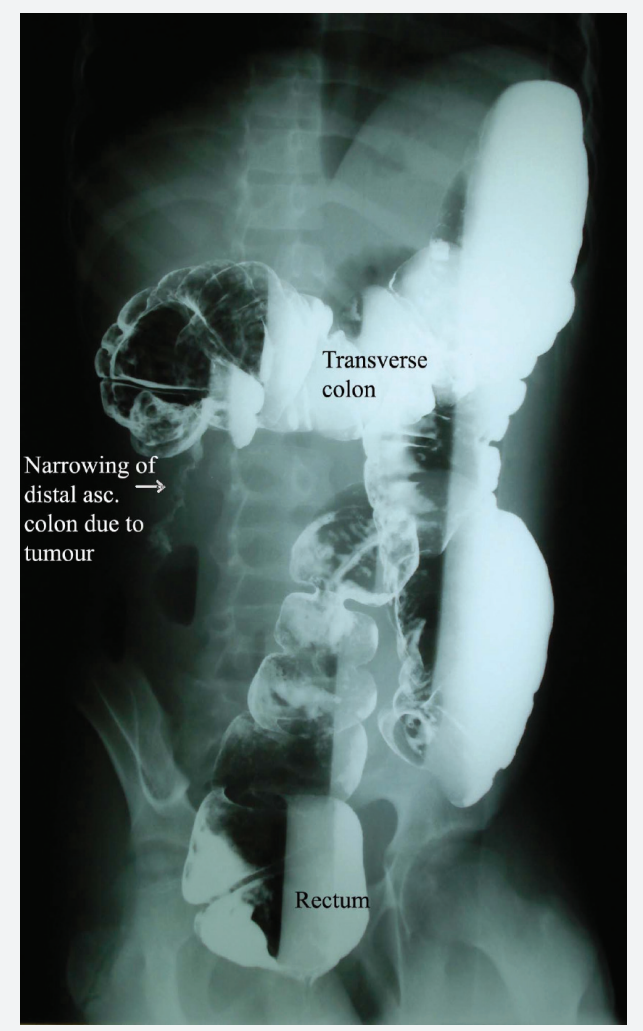

Figure 1: Free flow of contrast upto the ascending colon

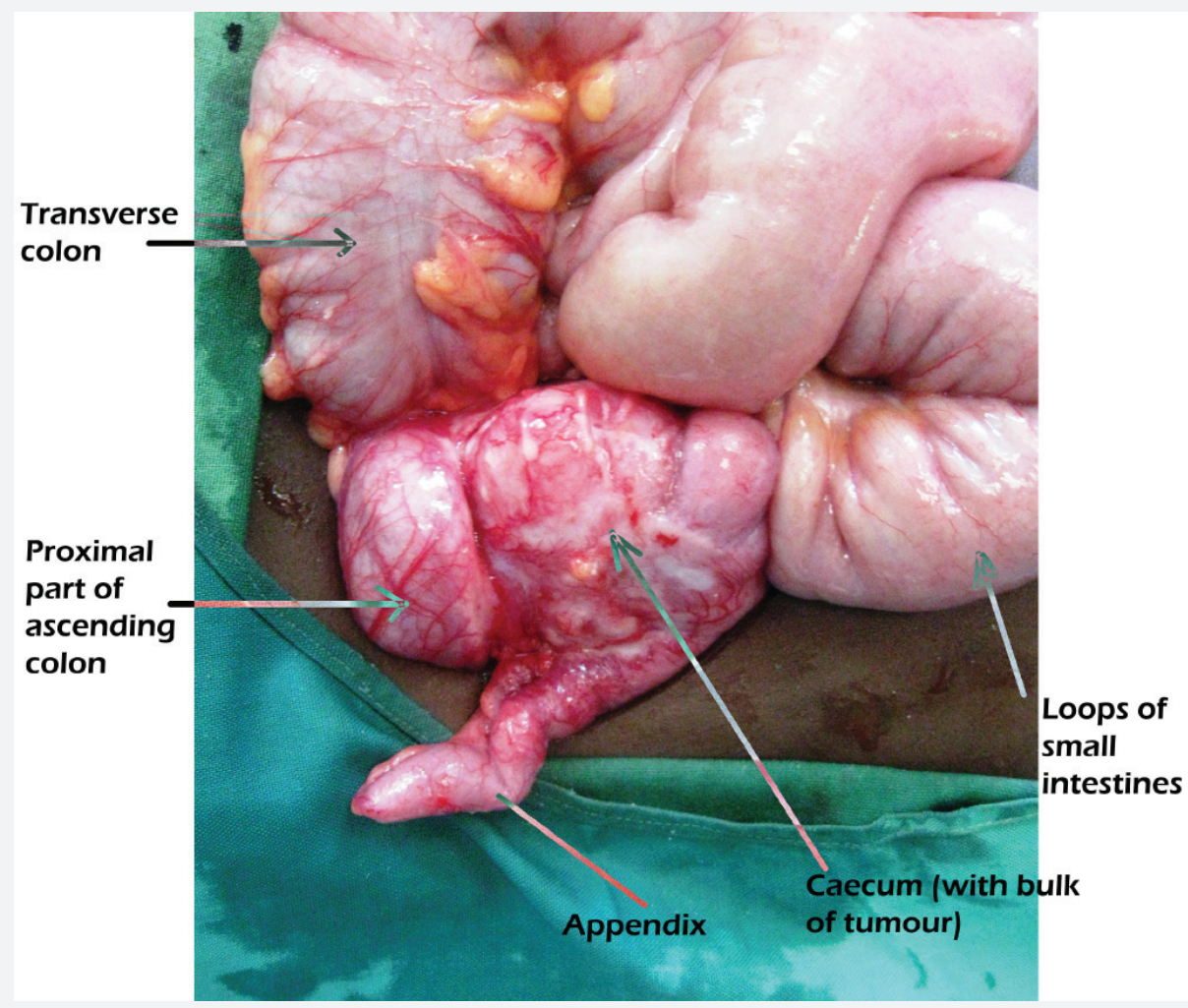

Figure 3: Right iliac fossa mass on breaching the abdomen 
on auscultation. Appropriate antibiotic treatment was initiated and the rest of her post operative recovery was uneventful. At pathology, the total length of resected gut was $35 \mathrm{~cm}$ with the tumour measuring $9 \times 6 \mathrm{~cm}$. The tumour involved the entire thickness of the wall circumferentially constricting the caecum and ascending colon. Enlarged mesenteric nodes were evident. No evidence of polyps was noted. The growth was a poorly differentiated mucin secreting adenocarcinoma at histology. It involved the whole colonic wall. The proximal and distal margins of resection were free of tumour. There was also involvement of mesentery, and blood vessels. Five lymph nodes were identified, with level II lymph node metastasis. The pathological stage was denoted T3, N2, $\mathrm{Mx}$ (Dukes stage $\mathrm{C}$ ). The patient was then referred to an oncologist and was due to start on a course of chemotherapy: Folinic acid (leucovorin), 5-Fluorouracil, Oxaliplatin (FOLFOX regimen).

However, she was readmitted four months later with features of intestinal obstruction. She had been unwell for a duration of two weeks prior to this admission. She was sick looking and the abdomen distended with an ill-defined right iliac fossa mass. Plain radiographs showed multiple lengthy air-fluid levels within the small intestines.

Because of persistent obstructive symptoms, the abdomen was explored. The intraoperative findings this time included widespread metastatic nodules on the greater omentum, small intestines, the entire peritoneal lining and the liver. A $15 \mathrm{~cm}$ diameter recurrent mass was found at the site of the previous anastomosis with dilated small bowel loops (fig. 5). Excision of the tumour was performed with primary ileo-transverse anastomosis and omentectomy. The patient showed poor response post operatively and died 1 week later.

\section{Discussion}

Adenocarcinoma of the colon and rectum is the most common cancer of the gastrointestinal tract. Generally

\begin{tabular}{lll} 
Parameter & Adult & Children \\
Incidence & Common & Rare \\
\hline Presentation & Intestinal obstruction in 16-35\% & Intestinal obstruction in 70\% \\
\hline M:F ratio & $1: 1$ & $2: 1$ \\
\hline Stage at presentation & $50-60 \%$ in Dukes stage C \& D & $60-80 \%$ in Dukes stage C \& D \\
\hline Primary site & $70-75 \%$ in rectosigmoid region & $30-35 \%$ in rectosigmoid region \\
\hline & & $40-60 \%$ in right colon \\
\hline Histopathology & $5 \%$ mucinous & $50 \%$ mucinous \\
\hline Surgical respectability & $90-95 \%$ & $40 \%$ \\
\hline Ovarian metastasis & $4 \%$ & $22 \%$ \\
\hline CEA level & Important tumour marker & Not reliable \\
\hline Delay in diagnosis & $15 \%$ & $60 \%$ \\
\hline Prognosis & Better & Poor \\
\hline
\end{tabular}

Table I-Colorectal adenocarcinoma: Differences between Adults and Children $(1,5,16,20,22,23)$

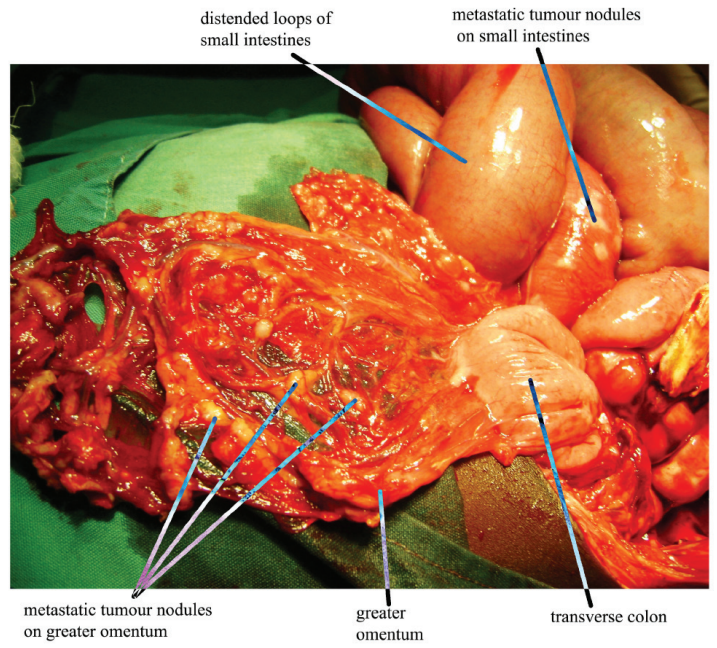

metastasis

it is a disease of older age groups beginning after the age of 40 to 45 years and peaking between 75 and 80 years $(14,15)$. Colorectal cancer is extremely rare in childhood and adolescence, the incidence being $1.3-2$ cases per million population $(8,14,16)$.

Contrary to adult patients in whom a predisposing history of familial polyposis syndromes, hereditary nonpolyposis syndromes, ulcerative colitis, or colorectal cancer in relatives can be sought, most paediatric patients develop de novo carcinoma in a previously normal colon $(6,8,17-19)$. In a category of patients with colorectal carcinoma at a very young age but who do not have a family history of HNPCC, results suggest that they harbour tumours with a defect characteristic of mismatch repair 
Adenocarcinoma of the Colon in a $\mathbf{1 0}$-year-old child

Siboe M. M. , Abdalla R. O. , Lakati K.C., Oduor P.
(MMR) deficiency and that many of these have germline mutations of an MMR gene $(12,13)$.

In children and adolescents, it is associated with a significantly worse survival rate likely because of delay in the diagnosis, advanced stage of the disease at presentation, with approximately $60-80 \%$ of patients at Dukes stage $\mathrm{C}$ or $\mathrm{D}$ and poor histological differentiation of the malignancy $(1,5-8,20)$.

Symptoms are related to the primary site of the tumour within the large bowel. In children and adolescents, as with our patient, these may be vague abdominal discomfort, changes in bowel habit, anaemia and gastrointestinal bleeding. These vague symptoms and decreased awareness among clinicians contribute to a delay in diagnosis $(1,21)$.

The differences in duration of symptoms, primary site, pathological findings, stage and prognosis between adults and children is striking as seen in Table I.

Histologically, mucin-producing or signet ring adenocarcinoma is the predominant cell type occurring in $50 \%$ of paediatric cases as compared to $5 \%$ in adults $(5,6,22)$. The mucin absorbs water, swells, and invades tissues, thus promoting tumour growth and spread of malignant cells. It also interferes with the immune recognition of carcinoma cells by the mucopolysaccharide coating $(11,16,20,24)$.

Patients may test positive for occult blood in stool. However, this has not proven to be of significant value in the treatment of paediatric patients (4). Levels of carcinoembryonic antigen (CEA) should be determined despite the fact that fewer than $75 \%$ of colon carcinomas in children produce it. It is a useful tool in identifying recurrent disease after resection $(23,25)$.

Surgery is the mainstay of treatment. Radical resection of the involved colon and its mesentery, usually in the form of a hemicolectomy, is the treatment of choice.

The role of adjuvant chemotherapy in children and adolescents is controversial. Adjuvant chemotherapy has not been reported to result in cure in metastatic disease. Similarly, radiation has little to offer except when the tumour involves the rectosigmoid and anal area (1).

\section{Conclusion}

Based on age alone, cancer of the colon should not be excluded as a clinical diagnosis. We emphasize that the possibility of a malignant colorectal tumour should be considered for any child with signs and symptoms of in- testinal obstruction, intractable abdominal pain, alteration in bowel habits and gastrointestinal bleeding. This case is presented to draw attention to a disease in which the prognosis might be improved, by the wider recognition of its occurrence in childhood.

\section{Acknowledgements}

To the patient's guardians for giving consent for this case to be published and to Dr. J. M. Wachira, Dr. E. Karau and Dr. H. Saidi for all their assistance, support and constructive criticism.

\section{References}

1. Sarin YK, Jacob S, Prahbakar BR, Shah R. Adenocarcinoma colon. Indian Pediatr 1997;34:345-8

2. Steinberg JB, Tuggle DW, Postier RG. Adenocarcinoma of the colon in adolescents. Am J Surg 1988;156:460-2

3. Kern WH, White WC. Adenocarcinoma of the colon in 9-month-old infant. Cancer 1958;11:855-7

4. Pizzo PA, Paplack DG. Principles and practice of pediatric oncology. 4th edition. Philadelphia(Pa): Lippincott Williams \& Wilkins; 2002.

5. Chana RS, Mubashir M, Bhatt ML, et al. V. Rectal carcinoma in a 12-year-old boy. J Ind Assoc Ped Surg 2001 OctDec;6:152-6

6. Shatrughan PS, Bhupendra KJ, Mamta L, Sudha R. Mucinous carcinoma of rectosigmoid in a 15 -year-old child. Indian J Pathol Microbiol 2002;45(1):115-8

7. Shah RS, Pikale HS, Birmole BJ, Borwankar SS. Adenocarcinoma of the colon in a child. J Postgrad Med 1992;38(2):813

8. Karnak I, Arbay OC, Mehmet ES, Nebil B. Colorectal carcinoma in children. J Pediatr Surg 1999;34:1499-504

9. Musa AA, Agboola AOJ, Banjo AAF, Shonubi AMO. Rectal carcinoma in a nine year old Nigerian male child. EAMJ 2007 Feb;84(2):93-6

10. Donaldson MH, Taylor P, Rawitscher R, Sewell JB, Jr. Colon carcinoma in childhood. Paediatrics 1971;48:307-12

11. Kravarusic D, Feigin E, Dlugy E, et al. Colorectal carcinoma in childhood: a retrospective multicenter study. J Ped Gastro \& Nutr 2007; 44: 209-211

12. Liu B, Farrington SM, Petersen GM, et al. Genetic instability occurs in the majority of young patients with colorectal cancer. Nature Medicine 1995;1(4):348-52

13. Naccarati A, Pardini B, Hemminki K, Vodicka P. Sporadic colorectal cancer and individual susceptibility-a review of the association studies investigating the role of DNA repair 
genetic polymorphisms. Mutation Research 2007;635:11845

14. Rao BN, Pratt CB, Fleming ID, et al. Colon carcinoma in children and adolescents. Cancer 1982 April 15;49(8):171620

15. Sabiston textbook of surgery: the biological basis of modern surgical practice. 18th edition. USA: W.B. Saunders Company; 2007.

16. Odone V, Chang L, Caces J, et al. The natural history of colorectal carcinoma in adolescents. Cancer 1982 April 15;49(8):1716-20

17. Hsiang-Hung S, Chung-Ching L, Mao-Meng T, et al. Adenocarcinoma of the colon in children presenting as abdominal pain. Chang Gung Med J 2002;25:349-54

18. Sherlock P, Liping M, Winawar SJ. Predisposing factors in carcinoma of colon. Adv Internal Med 1975;20:121-50

19. Chopra R, Masih K. Adenocarcinoma of the colon in children and adolescents. Indian J Pathol Microbiol 1992;35:370-4

20. Sarda DK, Kamble AT, Mungate GS, Gosavi A. Mucinous carcinoma of rectum in an 11-year-old child. Indian J Surg 2004;66:236-8

21. Middelkamp JN, Haffner H. Carcinoma of the colon in children. Paediatrics 1963;32:558-71

22. Rose RH, Axelrod DM, Aldea Pa, Beck AR. Colorectal carcinoma in the young: a case report and review of the literature. Clin Pediatr (Phila) 1988 Feb;27(2):105-8

23. Angel CA, Pratt CB, Rao BN, et al. Carcinoembryonic antigen and carbohydrate 19-9 antigen as markers for colorectal carcinoma in children and adolescents. Cancer 1992 March 14;69(6):1487-91

24. Sharma MS, Kumar S, Agarwal N. Childhood colorectal carcinoma. African J Pead Surg 2009;6(1):65-7

25. Andrassy R, editor. Pediatric surgical oncology. W.B. Saunders Co; 1998 